\title{
VULNERABILIDADE DA POPULAÇÃO NEGRA E POLÍTICAS EDUCACIONAIS NO BRASIL
}

\author{
VULNERABILITY OF THE BLACK POPULATION AND \\ EDUCATIONAL POLICIES IN BRAZIL
}

\author{
Simone Maria Hüning ${ }^{1, *}$ \\ Aline Kelly da Silva² \\ Tathina Lúcio Braga Netto $^{3}$ iD
}

\begin{abstract}
RESUMO: No artigo, percorremos processos históricos que promoveram a vulnerabilidade da população negra brasileira. Analisamos documentos de políticas educacionais que tratam da inclusão de discussões raciais no currículo, do combate ao racismo e às desigualdades étnico-raciais. Dialogamos com o pensamento de autores como Foucault, Agamben e Mbembe e utilizamos ferramentas conceituais tais como biopolítica, racismo e necropolítica. Tomamos essas políticas como uma resposta estatal diante da vulnerabilidade social. Elas expressam conquistas e tensionamentos na relação entre a população negra e o Estado.
\end{abstract}

Palavras-chave: Vulnerabilidade. Racismo. Políticas educacionais.

\begin{abstract}
In the paper, we go through the historical processes that promoted the vulnerability of the Brazilian black population. We analyze educational policy documents that address the inclusion, in the curriculum, of racial discussions, and the fight against racism and ethno-racial inequalities. We engage in a dialogue with the theories of authors such as Foucault, Agamben, and Mbembe, and use conceptual tools, such as biopolitics, racism, and necropolitics. We take these policies as a State response to the resultant social vulnerability. They express achievements and tensions in the relationship between the black population and the State.
\end{abstract}

Keywords: Vulnerability. Racism. Educational policies.

1.Universidade Federal de Alagoas - Instituto de Psicologia - Maceió (AL), Brasil.

2.Universidade Federal do Rio Grande do Sul - Instituto de Psicologia - Porto Alegre (RS), Brasil.

3.Universidade Federal de Alagoas - Pró-Reitoria Estudantil - Palmeira dos Índios (AL), Brasil.

*Autora correspondente: simone.huning@ip.ufal.br

Número temático organizado por: Adriana da Silva Thoma (I.M.) e Betina Hillesheim

Esta pesquisa foi financiada pelo Conselho Nacional de Desenvolvimento Científico e Tecnológico, processo no. 305364/2017-0. 


\section{Introdução}

"Ele não me viu com a roupa de escola?"

A pergunta foi do estudante negro Marcos Vinícius da Silva, de 14 anos, a sua mãe, após levar um tiro pelas costas durante uma operação policial no Complexo da Maré, zona norte do Rio de Janeiro, quando estava a caminho da escola, em 20 de junho de 2018 (BETIM, 2018). Sua interrogação, horas antes de morrer executado pela polícia, reverbera em nossa escrita, a qual objetiva analisar documentos de políticas educacionais que tratam da inclusão de discussões raciais no currículo, do combate ao racismo e às desigualdades étnico-raciais. Aqui discutimos políticas educacionais brasileiras para a população negra, formuladas como resposta estatal à vulnerabilidade social, que mantêm, porém, estreita relação com a discriminação racial em nossa sociedade e com os mecanismos de distribuição de riqueza e bens culturais.

Para Carneiro (2005), a problemática racial situa-se no plano teórico e da ação política, em que acontecem disputas para a implementação de políticas públicas para a reversão das condições desfavoráveis de vida nas quais se encontra a população negra no Brasil. Assim, o dispositivo de racialidade - construção e capilaridade do racismo e seus efeitos nos diversos campos da vida social de indivíduos, grupos, instituições e políticas estatais - pode ser compreendido como uma tecnologia que possibilita pensarmos a educação na produção de poderes, saberes e subjetividades.

Processos educacionais imbricam-se com produção de vulnerabilidade social, desde as apostas que são feitas nos currículos dos diferentes níveis de ensino até as políticas e condições de acesso e permanência de pessoas negras nessas instituições. Silva (2018) remete a vulnerabilidade a um limiar de indiscernibilidade entre vida e morte na lógica de segregação construída nas cidades. Entendemos que políticas públicas educacionais tanto podem provocar mudanças e rupturas nas condições de vulnerabilidade quanto podem reiterá-las.

Sustentamos nossa discussão na análise de documentos que visam à inclusão de discussões raciais e ao combate do racismo pelas políticas educacionais: a Lei n. 10.639/2003, que versa sobre a obrigatoriedade do ensino da história e cultura afro-brasileiras e africanas nos Ensinos Fundamental e Médio e institui o Dia da Consciência Negra; o Parecer CNE/CP n. 03/2004, que orienta as Diretrizes Curriculares Nacionais para a Educação das Relações Étnico-Raciais e para o Ensino de História e Cultura Afro-Brasileiras e Africanas; e a Resolução CNE/CP n. 01/2004, que institui Diretrizes Curriculares Nacionais para a Educação das Relações Étnico-Raciais e para o Ensino de História e Cultura Afro-Brasileiras e Africanas. Não nos restringimos, porém, a esses documentos, dialogando com outras legislações que tomam a desigualdade étnico-racial como seu alvo. Para tanto, partimos de ferramentas teórico-conceituais da genealogia foucaultiana, em articulação com o pensamento de Giorgio Agamben e Achille Mbembe.

\section{Entre Políticas de Vida e de Morte}

Dois conceitos propostos pelo filósofo francês Michel Foucault estão na base de nossas reflexões: biopolítica e racismo de Estado (FOUCAULT, 2008). Embora ambos sejam amplamente utilizados para a problematização do presente, particularmente nos campos de políticas públicas, autores contemporâneos como Giorgio Agamben e Achille Mbembe sinalizam limites das formulações foucaultianas e colocam outras questões para pensarmos as políticas que tomam a vida e, sobretudo, a morte como alvos na atualidade.

Agamben retoma o conceito de biopolítica apontando uma lacuna no trabalho do autor francês sobre os campos de concentração nazistas. Para Agamben (2002), o campo faz emergir a tanatopolítica, na qual as linhas que separam poder sobre vida e morte tornam-se indiscerníveis e móveis. A articulação do 
trabalho de Agamben às teorizações foucaultianas possibilita uma complexificação do pensamento. Ainda assim, ambos são europeus que elaboram seus conceitos basicamente a partir de análises de experiências da Europa Ocidental. Partimos, então, para um terceiro autor, que coloca em análise o racismo produzido pelos processos de colonização dos europeus sobre os países da África, das Américas e do Caribe.

Para Mbembe (2016), é preciso que se diga sobre que territórios e sujeitos incide esse poder de transformar pessoas em "mortos-vivos" (MBEMBE, 2016, p. 146). O autor argumenta que os corpos historicamente tomados como alvo de uma biopolítica - que, cada vez mais, passa a ser exercida como necropolítica -, são os corpos negros. Desse modo, afirma que a raça foi a sombra sempre presente sobre o pensamento e a política ocidentais, especialmente quando se trata de imaginar a desumanidade de povos estrangeiros - um outro que não tem sua existência humana reconhecida - ou dominá-los. A escravidão foi uma das primeiras instâncias de experimentação biopolítica, intrinsecamente relacionada ao surgimento do terror de guerra na modernidade.

Assim, Mbembe (2018) não situa o conceito de raça como uma questão a ser posta em termos de igualdade e diferença, mas como operador político resultante de processos históricos da modernidade, nos quais se encontra também a emergência do capitalismo. Negro é o simulacro com o qual foi revestida a população do continente africano, desde o sistema de plantação até as formas mais contemporâneas de exploração capitalista. Negra(o) é aquela(e) cuja carne foi transformada em coisa e o espírito, em mercadoria. A fabricação racial, ou o processo de racialização das categorias branco e negro, é efeito de uma invenção europeia, que serve à extração da mais-valia, à exploração de recursos em países colonizados e à coisificação do outro. Desse modo, a atribuição do substantivo "negro" a determinados sujeitos é uma condição de possibilidade para a vulnerabilidade social de segmentos populacionais, já que opera materialidades e hierarquizações em torno do binômio branco-negro.

Nessa perspectiva, a raça é uma ficção ocidental útil ao capitalismo, uma fabricação realizada para manter certas populações à margem da cidadania e dos direitos, em situações de exclusão, vulnerabilidade, abandono social e até mesmo descartabilidade (MBEMBE, 2018). O conceito de raça é, assim, indissociável da violência no bojo do capitalismo e do neoliberalismo contemporâneos, nos quais as políticas públicas estatais emergem como estratégias de governo das populações e de gerenciamento das desigualdades sustentadoras dessa mesma lógica neoliberal.

\section{Vulnerabilização da População Negra Brasileira}

A vulnerabilidade produzida pela raça possui territórios e endereçamentos marcados pelas relações de colonização e escravidão. O número de homicídios de pessoas negras no Brasil, em 2014, foi 158,9\% maior que o de pessoas brancas (WAISELFISZ, 2016). No que tange a escolarização, constatou-se, em 2010, que, conforme aumentam os anos escolares, há uma evasão da população negra, que consiste em apenas 15,9\% de estudantes do Ensino Superior (BRASIL, 2014). O analfabetismo, conforme dados de 2016 do IBGE, atingia níveis de $11 \%$ na população negra em comparação com 5\% para a população branca, e a população negra consistia em 70\% dos que viviam em situação de extrema pobreza (BRASIL, 2017).

Nossa história é marcada pela segregação racial, endossada por discursos que forjaram a população negra como um inimigo que obstruiria o desenvolvimento do país. Após a proclamação da Lei Áurea, a ausência de políticas reparatórias pelos danos e violências sofridos durante o período escravocrata, bem como da oferta de condições dignas de subsistência, produziu e segue produzindo efeitos de marginalização e vulnerabilização.

No período da abolição, o país vivenciava a adoção, pela elite brasileira, de uma ideologia de supremacia racial iniciada nos anos 1870, seguindo forte no período de 1880 a 1920, a qual pregava que 
somente um país branco seria capaz de realizar os ideais do liberalismo e do progresso (JACCOUD, 2009). Nos primeiros anos do século XX, disseminou-se a ideia de que as epidemias eram culpa da(o) negra(o), recém-liberta(o), além da crença de a(o) descendente afro pertencer a uma raça inferior (DIWAN, 2007).

Fracassando em eliminar as pessoas negras da sociedade, o Brasil passou por tentativas de branqueamento da população, forjando um dispositivo jurídico por volta de 1920: um projeto de lei, no parlamento brasileiro, que previa o bloqueio de imigração dessas pessoas. Não foi avante por ser considerado inócuo no período, tendo em vista que, com as políticas migratórias europeias e de branqueamento nacional, possivelmente o desaparecimento da(o) negra(o) seria iminente no país. Todavia, o tema foi posto em discussão novamente na Constituinte de 1930. Esse ideal de branqueamento fortaleceu a ideia da necessidade de uma mestiçagem como caminho possível para uma relativa aceitação social (JACCOUD, 2009). Em meados do século XIX, a pessoa mestiça era vista como um risco de degeneração da nação (SILVA, 2010), sendo, posteriormente, considerada um elemento importante para o branqueamento do país. Domingues (2011) afirma que houve também a tentativa de branqueamento social; ou seja, de incorporar as pessoas negras à cultura branca, obrigando à renúncia da cultura afro-diaspórica.

\section{Racismo e Políticas Educacionais no Brasil}

$\mathrm{Na}$ Constituição de 1934, formaliza-se a proposta de uma educação eugênica no país: "Art 138 - Incumbe à União, aos Estados e aos Municípios, nos termos das leis respectivas: [...] b) estimular a educação eugênica [...]" (POLETTI, 2012, p. 136-137). Durante o período pós-abolicionista, houve uma rejeição a estudantes negras(os) nas escolas, impedindo sua matrícula (DOMINGUES, 2008), elementos que contribuíram para a produção do analfabetismo da população negra e sua desvantagem no acesso a políticas educacionais, que marcam as relações étnico-raciais contemporâneas.

Contudo, em uma história caracterizada por violências, é fundamental assinalar que se constituíram movimentos de resistência. Mecanismos para criar melhores condições de vida para essa população começaram a ser produzidos por meio de associações para pessoas negras, com o intuito de estruturar instrumentos sociais, como a educação. De 1897 a 1930, havia cerca de 85 associações funcionando na cidade de São Paulo. O documento Juventudes Negras do Brasil - trajetórias e lutas traz a Frente Negra Brasileira (FNB) como importante movimento de resistência da década de 1930 (BARBOSA; SAMPAIO; BARBOSA, 2012). Segundo Domingues (2008), essa foi a maior e mais importante entidade negra do período pósabolicionista no Brasil, resultado do acúmulo de experiência organizativa de afro-paulistas. O movimento teve como marco a instrução de crianças e jovens com o propósito de educá-las(os) conforme suas próprias aspirações, considerando a educação a principal arma das(os) negras(os) naquele período.

Ao final da Segunda Guerra Mundial, diante dos efeitos que haviam sido produzidos pela política eugênica, os discursos sobre raça ganharam ênfases em seus aspectos social e cultural. Maio e Santos (2005) ressaltam que os estudos sobre relações raciais no Brasil, patrocinados pela Organização das Nações Unidas para a Educação, a Ciência e a Cultura (UNESCO), nos anos 1950 até 1960, revelaram as tensões entre o mito da democracia racial e o racismo brasileiro. Jaccoud (2009) aponta, no entanto, um período de apagão sofrido pelo movimento negro, que vinha ganhando força. De 1964, ano em que se instaurou a ditadura militar no Brasil, até o fim da década de 1970, houve um grande refluxo nos movimentos sociais de militância antirracistas.

A visibilidade da questão racial no Brasil voltou a tomar corpo no fim da década de 1980, quando o termo negra(o) passou a ser usado como palavra de ordem em um processo de autoafirmação identitário. Iniciou-se a discussão da inserção da(o) negra(o) na Constituição. Movimentos sociais se engajaram em encontros, congressos e convenções, sugerindo pautas como a criminalização do racismo e o direito à posse de terras para comunidades 
quilombolas (JACCOUD, 2009). Houve, então, grande influência de organizações internacionais que impunham ao Brasil o combate ao racismo como condição para o estabelecimento de acordos de mercado.

Nesse contexto, as discussões que antecederam a formulação da nova Constituição Federal de 1988 e a criação, pelo Ministério da Cultura, da Fundação Cultural Palmares, no mesmo ano - com a participação do movimento negro exigindo respaldo legal para reparar os danos sofridos por afrodescendentes -, foram pontos cruciais para o início de mudanças no campo do combate às desigualdades raciais no país. No entanto, o governo do presidente Fernando Henrique Cardoso (1995-2003), apesar de introduzir, em 1996, a Política de Valorização da População Negra no Programa Nacional de Direitos Humanos (PNDH), até meados de 2001, não havia conseguido cumprir as propostas aí estabelecidas (MAIO; SANTOS, 2005).

Naquele período, relatórios internacionais e eventos sobre racismo e políticas reparatórias ganhavam força mundialmente e organizações de movimentos negros denunciavam as desigualdades raciais no Brasil. Ainda assim, apenas em 2001 o país assumiu internacionalmente um compromisso de implementar políticas públicas para a população negra, a partir da III Conferência Mundial contra o Racismo, Discriminação Racial, Xenofobia e Intolerância Correlata, em Durban (JACCOUD, 2009). Logo após a conferência, em 2001, o Brasil definiu um programa de cotas no âmbito ministerial (o Ministério do Desenvolvimento Agrícola e Reforma Agrária e o Ministério da Justiça criaram programa de cotas raciais para a estrutura institucional; e o Ministério das Relações Exteriores, as bolsas-prêmio para a diplomacia). Tal ação motivou iniciativas nos âmbitos municipais e estaduais para a criação de sistema de cotas raciais.

No entanto, a despeito desses esforços, outras formas de racismo e invisibilização persistiram. Note-se que, da proclamação da abolição da escravidão no Brasil até a proposição formal da inclusão das questões étnicoraciais no sistema educacional, com vistas à redução da desigualdade, decorreram 115 anos. Apenas em 2003 foi promulgada a Lei n. 10.639, que alterou a Lei de Diretrizes e Bases da Educação Nacional (LDB) para incluir nos currículos da rede de ensinos Fundamental e Médio a obrigatoriedade da temática "História e Cultura AfroBrasileira”, instituindo, também, no calendário escolar, o dia Nacional da Consciência Negra (BRASIL, 2003). Até então o Brasil não possuía legislação federal com foco no combate ao racismo.

Apesar da mudança legislativa, Souza e Oliveira (2017) alertam que a determinação da LDB não ocorreu como deveria, pois esse conteúdo, em muitos casos, limita-se a ser trabalhado no período de celebração do dia da Consciência Negra, não sendo pertencente à matriz curricular fixa. Além disso, os autores denunciam a carência de material didático adequado. $\mathrm{O}$ mito da democracia racial parece, nesse sentido, não ser algo do passado, mas ainda vivenciado e sustentado também pela existência de uma lei que, por si só, pouco altera as práticas educacionais em curso.

Nas instituições de Ensino Superior, bem como naquelas que atuam em outros níveis da educação brasileira, com prioridade para as voltadas à formação de professoras(es), a inserção curricular da educação para questões étnico-raciais é orientada pela Resolução do Conselho Nacional de Educação/Conselho Pleno (CNE/CP) n. 01 de 17/06/2004 (BRASIL, 2004a). Juntamente com a Resolução, o Ministério da Educação publicou o Parecer CNE/CP n. 3/2004, fundamental para a compreensão dos objetivos das políticas afirmativas para afrodescendentes no campo educacional. Seu texto destaca os objetivos de combate ao racismo e às discriminações, de reconhecimento e valorização da história, da cultura, da identidade e da garantia do direito de as pessoas negras "se reconhecerem na cultura nacional, expressarem visões de mundo próprias, manifestarem com autonomia, individual e coletiva, seus pensamentos" (BRASIL, 2004b, p. 02). Na base do parecer CNE/CP n. 3/2004 estão o reconhecimento da violência imposta historicamente à população negra no Brasil, que a coloca em condição de desvantagem e vulnerabilidade, e o princípio de que o enfrentamento às formas de preconceito e discriminação requer políticas educacionais que questionem a desigualdade nas relações étnico-raciais e valorizem a diversidade. 
Para o Ensino Superior, é um marco a implantação das políticas afirmativas com a Lei n. 11.096/2005, que instituiu o Programa Universidade para Todos (Prouni) e definiu a obrigatoriedade de reserva de um percentual de bolsas de estudo para pessoas autodeclaradas indígenas, pardas ou negras. A chamada política de cotas foi implementada com base em pesquisas que apontavam para a quase ausência de pessoas negras na universidade. A população negra consistia, em 1988, em 3,6\% do total de estudantes e, em 2008, após a política de cotas, passou para 16,4\% da população universitária (ARTES; RICOLDI, 2015). Mesmo com um aumento importante no acesso, persiste grande desigualdade em relação à população branca.

Dispondo especificamente sobre o ingresso nas universidades federais e nas instituições federais de ensino técnico de nível médio, em 2012 foi promulgada a Lei n. 12.711, prevendo reserva de vagas para pessoas autodeclaradas pretas, pardas e indígenas, e considerando a proporcionalidade entre a composição étnico-racial da população e o acesso ao Ensino Superior como estratégia para enfrentar o problema do racismo institucional no país. Por fim, consideramos importante mencionar a Portaria n. 389/2013, que institui bolsas de permanência para a população quilombola, além da indígena. Esse programa tem como uma de suas finalidades minimizar desigualdades étnico-raciais, porém, recentemente vem sendo alvo de cortes significativos, recolocando em pauta a fragilidade das políticas afirmativas e a vulnerabilidade da população-alvo.

\section{Tensionamentos Políticos}

Nas tramas das relações de saber-poder, delineiam-se jogos entre visibilidades e invisibilidades. A Lei n. 10.639/2003 dispõe sobre a inserção de conteúdos curriculares sem mencionar dispositivos necessários para garantir efetivamente a inclusão da história e da cultura afro-brasileiras e africanas nos currículos, ao mesmo tempo que produz esquecimentos quanto ao Ensino Superior. O parecer CNE/CP n. 3/2004 e a resolução CNE/CP n. 1/2004 buscam ampliar o debate das relações raciais para a formação de professoras(es), inclusive no Ensino Superior, e apresentam princípios para o combate ao racismo e reeducação das relações étnico-raciais na interface com outras instituições e com os movimentos sociais negros. Entretanto, são instrumentos jurídicos com menos poder normativo, acarretando fragilidades na observância dos princípios e na destinação de recursos para a execução de ações no sistema educacional.

Um ponto forte do Parecer CNE/CP n. 03/2004 é que ele considera que discutir as desigualdades étnico-raciais não é somente tarefa dos espaços educacionais, explicitando a necessidade de fortalecer em outros espaços sociais o debate e a criação de ações de combate ao racismo. Entretanto, como o Parecer CNE/CP n. 03/2004 e a Resolução n. 01/2004 indicam somente princípios e diretrizes para a inserção de ações afirmativas nos currículos, o modo como serão implantadas tais ações fica a cargo dos estabelecimentos de ensino. A resolução estabelece, em seu artigo terceiro, inciso primeiro, que os sistemas de ensino e as entidades mantenedoras serão responsáveis por criar condições materiais e financeiras para o provimento de material bibliográfico e de outros materiais didáticos necessários para a educação das relações étnicoraciais (BRASIL, 2004a).

Dessa maneira, a efetivação das ações fica a critério dos contextos locais e depende de uma boa vontade que a torna incerta. Assim, políticas afirmativas garantidas em documentos, mas sem previsão de recursos e dispositivos para sua operacionalização, perpetuam situações de vulnerabilização da população negra, que também se produz quando certos direitos ficam à margem de prioridades estatais. O exposto nos permite seguir os deslocamentos nos modos como o Estado governa essa população. Se, no início do século XX, o Brasil promulgava leis eugênicas no campo educacional e, posteriormente, por longas décadas, silenciou a respeito da desigualdade étnico-racial, como, com especial força a partir do início dos anos 2000, essa população começa a ser alvo de políticas de reparações e ações afirmativas? 


\section{(Necro)Políticas Educacionais}

O início da execução de políticas afirmativas no país foi uma construção notadamente motivada pela pressão de movimentos sociais e organismos internacionais. No contexto mundial pó-Segunda Guerra, o discurso científico da eugenia perdeu forças por sua proximidade aos preceitos nazistas. Fortaleceu-se uma postura de combate ao racismo como consequência do ativismo dos movimentos sociais e o protagonismo do movimento negro foi impulsionado também por uma conjuntura política vinculada à diplomacia internacional. A implementação de políticas afirmativas ganhou espaço conforme o neoliberalismo impôs a necessidade de equilíbrio interno dos países que pretendiam compor a rede de relações comerciais internacionais. A "paz mundial" favoreceu o mercado internacional, principalmente dos países colonizadores. Isso, porém, não garantiu que, sob esse mesmo discurso pacifista, tais países deixassem de impor guerra aos colonizados, tampouco significou que o Brasil resolvesse, de fato, o problema da desigualdade racial.

Nessa conjuntura, a educação - um dos direitos mais deficitários para a população negra - foi exigida como condição para o estabelecimento das relações de mercado, impulsionando, em seu âmbito, a formulação das políticas afirmativas raciais. No Brasil, tais políticas somente começaram a ser elaboradas após o país tornar-se signatário de importantes acordos e tratados internacionais, na tentativa de provar que providências estavam sendo tomadas para reduzir as desigualdades.

Há mais de dez anos da implementação das políticas educacionais reparatórias com vistas ao combate ao racismo e à desigualdade racial, a vida da população negra no Brasil ainda é marcada pelo preconceito. A deficiente estruturação da política de inclusão educacional no Ensino Superior é uma das barreiras, pois, apesar de colher resultados positivos, as cotas estão longe de se fazer desnecessárias e plenamente estruturadas (QUEIROZ, 2004; FIGUEIREDO; GROSFOGUEL, 2009).

Outra dificuldade na efetivação dessas políticas é a refutação das desigualdades decorrentes das relações raciais no país pela atribuição das diferenças de acesso exclusivamente a questões de ordem socioeconômicas. São, assim, forjadas tentativas de enfraquecer a necessidade das ações reparatórias. Enquanto o movimento negro ainda luta pela plena estruturação de políticas educacionais inclusivas, há uma discussão no Brasil sobre sua legitimidade, levando, em 2012, à pauta do STF o julgamento de ações e Recurso Extraordinário: a Arguição de Descumprimento de Preceito Fundamental (ADPF) n. 186 e o Recurso Extraordinário (RE) n. 597.285 contestam a constitucionalidade e legitimidade da política de cotas; e a Ação Direta de Inconstitucionalidade (ADI) n. 3330 contesta a reserva de vagas por critério racial do Prouni (BRASIL, 2012a). No âmago desses pleitos judiciais, questiona-se a igualdade de acesso ao ensino, supostamente prejudicada pelas cotas raciais. No RE n. 597.285, afirma-se que essa política é um "verdadeiro pacto de mediocridade" (BRASIL, 2012b, p. 3) e que, "pelo fato de impor distinção de tratamento com base em critério étnico, incorre em verdadeiro crime de racismo" (BRASIL, 2012b, p. 4).

Esses processos expõem a racionalidade branca de democracia racial no país. Um discurso estruturado principalmente pelo medo da perda de privilégios das pessoas brancas, os quais permitem, automaticamente, o acesso aos lugares de poder e respeito. Evidencia-se a complexidade desse problema quando deparamos com a afirmação de Mbembe (2018) de que a sociedade branca anseia pelo apartheid, coisificando corpos negros. A subjugação das pessoas negras como raça marginalizada atribui a elas os espaços subalternos de trabalho, renda e morte. A negação da existência do racismo é, assim, um projeto necropolítico.

Consideramos indiscutível a relevância do sistema educacional como ferramenta para o combate ao racismo institucional no Brasil, bem como a inclusão curricular da educação para as relações étnico-raciais e as ações afirmativas. Contudo, essas iniciativas não podem ser discutidas sem se apontar também suas 
fragilidades e o modo como foi tardia, no contexto nacional, a proposição de políticas reparatórias no campo educacional. Isso coloca tal sistema, historicamente, como produtor de assimetrias raciais, aspecto evidente pelo próprio fato de que a inclusão da educação para as relações étnico-raciais, do ensino de história e cultura afro-brasileiras e africanas, nos diferentes níveis de escolarização, tenha sido feita a partir da determinação da lei apenas em 2003, encontrando ainda muitos entraves para sua efetivação.

Sendo essas políticas tão recentes, num país marcado pelo racismo, uma lacuna se coloca entre a "boa vontade" para a promoção dessas políticas e os recursos pedagógicos materiais e humanos para sua realização. A previsão da lei não resolve o apagamento dessas questões dos currículos nem a ausência de debates sobre as desigualdades e os conflitos étnico-raciais no cotidiano das instituições educativas, em quaisquer níveis de ensino, bem como na sociedade, de forma mais ampla.

A ausência dos temas étnico-raciais é também efeito da imposição da branquitude em nossa estrutura de ensino - acesso discente e docente, materiais didáticos, currículos e bibliografias. Se há uma ficção na ideia de uma raça negra, que a retira da condição humana, seu correlato é a fantasia europeia da pessoa branca, que tem como um de seus efeitos a produção de extermínios (MBEMBE, 2018).

Baleado em uma operação policial no Complexo da Maré, Marcos Vinícius da Silva (14 anos), diz: "Mãe, eu sei quem atirou em mim, eu vi quem atirou em mim. Foi o blindado, mãe. Ele não me viu com a roupa de escola?” (BETIM, 2018). A política da raça, a política de morte, é exercida em territórios pobres e negros pelo mesmo Estado que formula políticas educacionais direcionadas à inclusão de discussões raciais no currículo, ao combate ao racismo e à redução de desigualdades étnico-raciais. Se a análise dessas relações e violências não compuser o cotidiano, seguiremos com reparação e inclusão ineficazes, nas políticas educacionais, concomitantemente à exclusão da proteção estatal.

\section{Contribuição das Autoras}

Conceptualização: Hüning SM, Silva AK, Braga Netto TL; Metodologia: Hüning SM, Silva AK, Braga Netto TL; Redação - Primeira versão: Hüning SM, Silva AK,Braga Netto TL; Redação - Revisão \& Edição: Hüning SM, Silva AK, Braga Netto TL.

\section{REFERÊNCIAS}

AGAMBEN, G. Homo Sacer. O poder soberano e a vida nua I. Trad. Henrique Burigo. Belo Horizonte: UFMG, 2002.

ARTES, A.; RICOLDI, A. M. Acesso de Negros no Ensino Superior: o que mudou entre 2000 e 2010. Trad. Maria Luisa Prandina Rodrigues. Cadernos de Pesquisa, São Paulo, v. 45, n. 158, p. 859-881, out./dez. 2015. https://doi.org/10.1590/198053143273

BARBOSA, C. F.; SAMPAIO, G. S. B.; BARBOSA, S. M. F. (orgs.). Juventudes negras do Brasil - trajetórias e lutas. São Paulo: Observatório de Juventudes Negras, 2012. Disponível em: http://library.fes.de/pdf-files/ bueros/brasilien/11530.pdf. Acesso em: 23 jun. 2018.

BETIM, F. Mãe de jovem morto no Rio: "É um Estado doente que mata criança com roupa de escola". El País Brasil, 22 de junho de 2018. Disponível em: https://brasil.elpais.com/brasil/2018/06/22/ politica/1529618951_552574.html. Acesso em: 23 jun. 2018. 
BRASIL. Lei n. 10.639, de 9 de janeiro de 2003. Altera a Lei n. 9.394, de 20 de dezembro de 1996, que estabelece as Diretrizes e Bases da Educação Nacional, para incluir no currículo oficial da Rede de Ensino a obrigatoriedade da temática "História e Cultura Afro-Brasileira", e dá outras providências. Diário Oficial da União, Brasília, DF, 10 jan. 2003. Disponível em: http://www.planalto.gov.br/ccivil_03/Leis/2003/L10.639.htm. Acesso em: 23 jun. 2018.

BRASIL. Conselho Nacional de Educação. Resolução n. 1, de 17 de junho de 2004. Institui Diretrizes Curriculares Nacionais para a Educação das Relações Étnico-Raciais e para o Ensino de História e Cultura Afro-Brasileira e Africana. Diário Oficial da União, Seção 1, Brasília, DF, p. 11, 22 jun. 2004a. Disponível em: http://portal.mec.gov.br/cne/arquivos/pdf/res012004.pdf>. Acesso em: 23 jun. 2018.

BRASIL. Conselho Nacional de Educação. Parecer CNE/CP n. 03/2004. Diário Oficial da União, Brasília, DF, 19 maio 2004b. Disponível em: http://portal.mec.gov.br/dmdocuments/cnecp_003.pdf. Acesso em: 23 jun. 2018.

BRASIL. Supremo Tribunal Federal. STF julga nesta quarta (25) ações contra cotas em universidades públicas. Notícias STF: Brasília, 2012a. Disponível em: http://www.stf.jus.br/portal/cms/verNoticiaDetalhe. asp?idConteudo=205659 Acesso em: 24 jun. 2018.

BRASIL. Supremo Tribunal Federal. Recurso Extraordinário 597.285. Rio Grande do Sul. Política de ações afirmativas. Ingresso no Ensino Superior. Uso do critério étnico-racial. Autoidentificação. Reserva de vaga ou estabelecimento de cotas. Constitucionalidade. Recurso improvido. Julgamento em 9 de maio de 2012. 9 de maio de 2012b. Disponível em: http://redir.stf.jus.br/paginadorpub/paginador.jsp?docTP=TP\&docID=5455998 Acesso em: 23 jun. 2018.

BRASIL. Ministério da Educação. Portaria n. 389. Cria o Programa Bolsa-permanência e dá outras providências. Diário Oficial da União, Brasília, DF, 13 maio 2013. Disponível em: http://sisbp.mec.gov.br/ docs/Portaria-389_2013.pdf. Acesso em: 24 jun. 2018.

BRASIL. Plano Juventude Viva: Guia de Implementação para Estados e Municípios. Secretaria Nacional de Juventude. Brasília, DF, 2014. Disponível em: http://juventude.gov.br/articles/participatorio/0009/4790/ Guia_Plano_JuvViva_Final.pdf. Acesso em: 19 jun. 2018.

BRASIL.Índice de Vulnerabilidade Juvenil à Violência 2017: desigualdade racial, municípios com mais de 100 mil habitantes. Brasília, DF, 2017. Disponível em: http://unesdoc.unesco.org/images/0026/002606/260661 por. pdf. Acesso em: 21 jun. 2018.

CARNEIRO, A. S. A construção do outro como não-ser como fundamento do ser. 2005. 339 f. Tese (Doutorado em Educação) - Programa de Pós-graduação em Educação, Universidade de São Paulo, São Paulo, 2005.

DIWAN, P. Raça Pura. Uma história da eugenia no Brasil e no mundo. São Paulo: Contexto, 2007.

DOMINGUES, P. Um "templo de luz": Frente Negra Brasileira (1931-1937) e a questão da educação. Revista Brasileira de Educação, Rio de Janeiro, v. 13, n. 39, p. 517-596, set./dez. 2008. https://doi.org/10.1590/ S1413-24782008000300008

DOMINGUES, P. “Um desejo infinito de vencer”: o protagonismo negro no pós-abolição. Topoi, Rio de Janeiro, v. 12, n. 23, p. 118-139, jul./dez. 2011. https:// doi.org/10.1590/2237-101X012023007

FOUCAULT, M. Nascimento da Biopolítica: curso no Collège de France (1977-1978). Trad. Eduardo Brandão. São Paulo: Martins Fontes, 2008. 
FIGUEIREDO, A.; GROSFOGUEL, R. Racismo à brasileira ou racismo sem racistas: colonialidade do poder e a negação do racismo no espaço universitário. Sociedade e Cultura, Goiânia, v. 12, n. 2, p. 223-234, jul./ dez. 2009. https://doi.org/10.5216/sec.v12i2.9096

JACCOUD, L. A construção de uma política de promoção da igualdade racial: uma análise dos últimos 20 anos. Brasília: Ipea, 2009.

MAIO, M. C.; SANTOS, R. V. Política de cotas, os 'olhos da sociedade' e os usos da antropologia: o caso do vestibular da Universidade de Brasília (UnB). Horizontes Antropológicos, Porto Alegre, v. 11, n. 23, p. 181 214, jan./jun. 2005. https://doi.org/10.1590/S0104-71832005000100011

MBEMBE, A. Necropolítica. Trad. Renata Santini. Revista Arte \& Ensaios, Rio de Janeiro, v. 32, p. 122 -151, dez. 2016.

MBEMBE, A. Crítica da razão negra. Trad. Sebastião Nascimento. São Paulo: n-1 edições, 2018.

POLETTI, R. (1934). Constituições brasileiras. 3. ed. Brasília, DF: Senado Federal/Secretaria Especial de Editoração e Publicações/Subsecretaria de Edições Técnicas, 2012. v. III. Disponível em: http://www2.senado. leg.br/bdsf/bitstream/handle/id/137602/Constituicoes_Brasileiras_v3_1934.pdf. Acesso em: 23 jun. 2018.

QUEIROZ, D. M. O negro e a universidade brasileira. Historia Actual Online, Cádiz, n. 3, p. 73-82, 2004.

SILVA, M. L. Considerações sobre o dilema entre cor/raça/mestiçagem e ações afirmativas no Brasil. Reflexão e Ação, Santa Cruz do Sul, v. 18, n. 1, p. 8-29, 2010. https://doi.org/10.17058/rea.v18i1.1441

SILVA, W. V. N. Territórios vulneráveis: arquivos impróprios de uma memória em perigo. 2018. 169 f. Tese (Doutorado em Psicologia) - Programa de Pós-graduação em Psicologia Social e Institucional. Universidade Federal do Rio Grande do Sul, Porto Alegre, 2018.

SOUZA, I. L.; OLIVEIRA, L. C. Lei n. 10639/2003: o que mudou com relação ao racismo? Geledés, São Paulo, 2017. Disponível em: https://www.geledes.org.br/lei-no-10-639-2003-o-que-mudou-com-relacao-aoracismo. Acesso em: 24 jun. 2018.

WAISELFISZ, J. J. Mapa da Violência 2016: homicídios por armas de fogo no Brasil. Rio de Janeiro: Flacso, 2016. Disponível em: http://flacso.org.br/files/2016/08/Mapa2016_armas_web-1.pdf. Acesso em: 19 jan. 2020. 